\title{
Revising a Doctor of Nursing Practice Program in Response to Student Focus Group Feedback
}

\author{
Sheila Grossman \\ Fairfield University, sgrossman@fairfield.edu \\ Meredith Wallace Kazer \\ Fairfield University, mkazer@fairfield.edu \\ Nancy Moriber \\ Fairfield University, nmoriber@fairfield.edu \\ Patricia E. Calderwood

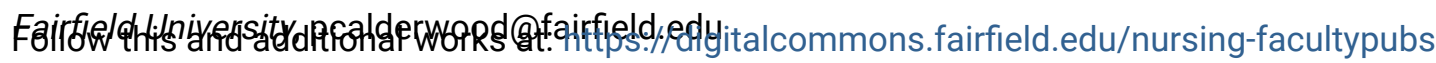 \\ Copyright 2016 Springer Publishing Company. Archived here with permission from the copyright \\ holder. Official version available at http://dx.doi.org/10.1891/2380-9418.9.1.51
}

\section{Peer Reviewed}

\section{Repository Citation}

Grossman, Sheila; Kazer, Meredith Wallace; Moriber, Nancy; and Calderwood, Patricia E., "Revising a Doctor of Nursing Practice Program in Response to Student Focus Group Feedback" (2016). Nursing and Health Studies Faculty Publications. 93.

https://digitalcommons.fairfield.edu/nursing-facultypubs/93

\section{Published Citation}

Grossman, Sheila, Meredith Wallace Kazer, Nancy Moriber, and Patricia Calderwood. "Revising a Doctor of Nursing Practice Program in Response to Student Focus Group Feedback." Journal of Doctoral Nursing Practice 9, no. 1 (2016): 51-54. 10.1891/2380-9418.9.1.51

This item has been accepted for inclusion in DigitalCommons@Fairfield by an authorized administrator of DigitalCommons@Fairfield. It is brought to you by DigitalCommons@Fairfield with permission from the rightsholder(s) and is protected by copyright and/or related rights. You are free to use this item in any way that is permitted by the copyright and related rights legislation that applies to your use. For other uses, you need to obtain permission from the rights-holder(s) directly, unless additional rights are indicated by a Creative Commons license in the record and/or on the work itself. For more information, please contact digitalcommons@fairfield.edu. 


\title{
Revising a Doctor of Nursing Practice Program in Response to Student Focus Group Feedback
}

\author{
Sheila Grossman, PhD, FNP-BC, APRN, FAAN \\ Meredith Wallace Kazer, PhD, CNL, APRN, A/GNP-BC, FAAN \\ Nancy Moriber, PhD, CRNA, APRN \\ Patricia Calderwood, $\mathrm{PhD}$ \\ Fairfield University, Connecticut
}

Keywords: doctor of nursing practice education; doctor of nursing practice; evaluation; immersion

\section{Introduction}

Throughout the history of professional nursing, changes in practice environments have guided changes in nursing educational systems. Over the past 50 years, advanced practice nurse roles have progressed in clinical practice and professional role requirements. The need to enhance the educational preparation in response to these requirements was addressed by the American Association of Colleges of Nursing (AACN, 2006). These "formative years in the development of the DNP" (Brown \& Crabtree, 2013, p. 330) resulted in several programs across the country with varying approaches to both advanced practice specialization and doctoral degree education. In addition, The Doctor of Nursing Practice: Current Issues and Clarifying Recommendations, the report from the Task Force on the Implementation of the DNP (AACN, 2015) suggests several recommendations to assist doctor of nursing practice (DNP) educators in the areas of DNP graduate scholarship, DNP project, resources, curriculum, practice rotations, and partnerships.

Although extensive work was done by faculty to develop the program, prepare for accreditation, and provide a quality program, continued data collection and response to student feedback is a necessary component of quality education and continuing accreditation. The purpose of this project is to describe the continued data collection process of the program, specifically regarding the immersion hours and development of the final project. Student data were collected through a focus group process and used to revise the program in response to feedback. Program evaluation and improvement is a necessary component of a DNP program, and it is our hope the evaluation and revisions discussed here may serve as a model for other programs also undergoing their formative years.

\section{Background}

Consistent with the AACN (2006) White Paper on DNP education, our program evolved with a strong emphasis on development of expert clinical practice. Although formal clinical experiences were planned to prepare clinicians, DNP students must also acquire increased knowledge, leadership, and practice expertise from immersion experiences. Riley and Beal (2013) suggest professional practice evolves, and this requires continuous learning. They found in their study on scholarly practice that nurses developed from unknowing to knowing that they needed more experience and learning. Certainly, master's of science in nursing (MSN) to DNP students realize, after graduating from their master's program, that, as advanced practice nurses, they require more knowledge and expertise than what they have been using in their practice. Bachelor of science in nursing (BSN) to DNP students do not have this experience prior to entering the DNP program. But they do readily differentiate between competencies gained from their direct patient clinical rotations versus indirect immersion hours. 
Carper's (1978) fundamental ways of knowing (empirical knowing, esthetic knowing, ethical knowing, and personal knowledge) provides a rationale for the significance of these immersion studies. In addition, KendallGallagher and Breslin (2013) recommend providing the DNP students opportunities to build a portfolio of adaptive leadership skills they can build throughout clinical practice and refine in immersion experiences. Thus, it is essential to evaluate and improve immersion experiences because this learning will greatly impact the ability of DNP graduates to transform health care. Clark and Allison-Jones (2011) cite new nursing roles are frequently identified because of local needs but often prior to developing standardized goals. Continuous development and improvement of the immersion component of DNP clinical hours will ultimately generate much needed leadership in increasing the quality of health care.

\section{Method}

After university institutional review board approval was obtained, all DNP students in their final year were invited to attend the focus groups. Students were told attendance is optional, informed consent would be required, and all data would be aggregated to provide anonymity. This sampling frame was chosen to ensure participants had sufficient time in the program to provide reliable reflections.

Focus groups were conducted during each seminar by a researcher from the Center of Academic Excellence. The 90-min focus meetings included introduction of the focus group facilitator and students, completion of informed consent, demographic form, a written focus survey (Table 1), and the oral focus group.

TABLE 1. Written Doctor of Nursing Practice Focus Group Questions

1. Do you feel you are receiving helpful advice and feedback from your faculty CPA during your immersion semesters? Any recommendations to improve this learning process?

2. Is there anything you would like to share about your immersion semesters and clinical preceptors?

3. Is there anything you would like to share about how your final project and presentation learning experience is going?

4. What were some of the best learning experiences that you had in your DNP seminar experience? How did your assigned faculty make for a positive experience?

5. How do you plan on making some practice improvements in your new role as a DNP?

6. Do you have any questions about your seminar, immersion experiences, or final project and presentation learning experience?

Note. $\mathrm{CPA}=$ clinical portfolio advisor; $\mathrm{DNP}=$ doctor of nursing practice.

\section{Results}

Three groups of students $(N=19)$ participated. The average age of the student participants was 37 years, and all were female except one. Fifteen of the participants (79\%) were BSN to DNP students, and the remaining 4 (21\%) were MSN to DNP students. As a result of the oral focus group, aggregated written responses produced four dominant themes: confusion about program requirements and expectations, a need for improved mentoring and advisement, a decided preference for a deepening rather than broadening of knowledge and skills required for advanced practice in their specialty, and reconfiguration of the scope and sequence of the courses.

\section{Theme 1-Confusion About Program Requirements and Expectations}

Feelings of confusion and anxiety about requirements and expectations, particularly about the final project/ presentation sequence were commonly expressed. Not every adviser was deemed sufficiently knowledgeable about requirements. Candidates agreed the catalog alone was not informative enough about the program structure. Participants suggested a flow chart be added to include when key choices occur throughout the program.

\section{Theme 2-Need for Improved Mentoring and Advisement}

Some students noted the importance of adviser ability to use portfolio, adviser responsiveness and availability, and especially the comprehensiveness of adviser knowledge about the program as a key factor in good advising. Many felt improved mentoring would assist in coordinating the immersion, choosing which patients to do case narratives, and developing personal objectives to create more of a seamless journey through the program. Most participants recommended partnering of the student and portfolio adviser in the first year. This would foster the identification of ideas to use for required course projects that would relate to final projects.

\section{Theme 3-Desire for a Deepening Rather Than Broadening of Knowledge and Skills}

There was a range of satisfaction among the students with their progress toward a culminating final project. Satisfactory progress seemed to mean all or most of the projects, papers, and professional experiences of their program were aligned conceptually and developed as a narrowing and deepening scope of a singular focus. Many have enjoyed making the immersion semesters "a more personal, tailored, independent experience." Some chose a focus at 
the beginning of their program and continued to study it in greater depth over time. These students were more successful in their progress than students who were not strategically directed in this way. Participants reinforced well-timed advice from the portfolio adviser to take this approach would have been helpful to those who didn't discover this path on their own. Several noted they had taken a somewhat scattershot approach (choosing new topics for each course because they seemed interesting) across courses, thus building a broad but comparatively shallow knowledge base. When asked if they would have preferred to be forced to choose a single focus at the outset of their program, most said yes. They explained their time, energy, and finances were limited, and a straight line to the finish would have made the most optimal use of all three. Students stressed they wanted more direction to hone in rather than expand outward across their studies.

\section{Theme 4-Reconfiguration of Scope and Sequence of Courses}

There was consensus the courses were not sequenced optimally, that research and community health content seemed redundant, and MSN to DNP students felt more content on advanced pharmacology and pathophysiology was needed. They recommended one DNP seminar remain in the final year and the other be introduced in the first year. In addition, nurse practitioner BSN to DNP students suggested the direct patient care clinical courses be taken before immersion.

\section{Discussion}

Standard IV-A, of the Commission on Collegiate Nursing Education (CCNE, 2013) criteria for the accreditation of DNP programs requires that "data on program effectiveness are used to foster ongoing program improvement" (p. 17). The survey undertaken represents our school's partial efforts to address these criteria. In addition, Standard III-H states "curriculum and teaching-learning practices are evaluated at regularly scheduled intervals to foster ongoing improvement" (CCNE, 2013, p. 16). In other words, once the data were collected, it is essential the faculty respond with meaningful changes to improve the program. Faculty agreed to the following changes (Table 2) based on

TABLE 2. Responses and Solutions to Doctor of Nursing Practice Students' Feedback

Student Concerns

1. Students felt that there were many changes in the program they were not notified about.

2. DNP seminars were sometimes seen as disorganized and did not always meet student's needs.

3. Because of the many program changes in this first BSN to DNP cohort, students would like a written and online flow chart to ensure consistency with program requirements.

4. There was some redundancy seen between the research and community health courses. The entire clinical direct patient care course sequence should be either before or after immersion.

5. Choosing a project topic early in the program was felt by students and faculty to be the best method to proceed through the DNP curriculum. Students did not believe this message was delivered clearly.

6. There is a need for students to select their faculty portfolio adviser (FPA) early in the program and that the role of this position needs to be defined more clearly.
Action Steps for Solution

The graduate program director (GPD) coordinated two open team-building meetings for students to come learn about program changes and build communication. All portfolio advisers will be oriented at beginning of each semester.

The GPD and the three seminar faculty revised objectives for each seminar to ensure organized and consistent content is being delivered across the three seminar sections. In addition, faculty agreed to move up the last semester of the DNP seminar (a one-credit seminar) to the second semester of the first year of each program. It was felt that a concentrated emphasis early in the program regarding selection of a scholarly project would be helpful.

The GPD updated the DNP handbook with the requested information, distributed to all students, and updated accordingly online.

The GPD organized meetings between course coordinators to examine perceived redundancies and all worked out solutions. Direct patient clinical rotations will be finished prior to or concurrent with immersion.

The GPD addresses this in the orientation and in NS 610: Advanced Nursing Roles E Reflective Practice and will continue to do so. The information was also added to the DNP handbook to ensure broader dissemination. Having a DNP seminar early in the program should assist students in making an early selection of a project topic.

The GPD will meet at the beginning of each semester and summer to review the FPA job description with all faculty involved that semester. In addition, an evaluation was developed for DNP students to evaluate their FPA and immersion experiences during the final immersion semester.

Note. $\mathrm{DNP}=$ doctor of nursing practice; $\mathrm{BSN}=$ bachelor of science in nursing. 
student feedback. DNP students have shared appreciation for the feedback, planned solutions, and suggested evaluation criteria regarding immersion experiences and scholarly project advisement.

\section{Conclusion}

The recent Institute of Medicine (IOM, 2011) report on the Future of Nursing states nurses must achieve higher levels of education and training in response to “... increasing [healthcare] demands" (p. 2). DNP programs are developing quickly in response to a need for expanding knowledge for advance practice nurses. This expanded knowledge is essential to position advanced practice nurses to become leaders across health care environments, consistent with the IOM (2011) report on the Future of Nursing.

Although students are meeting the program outcomes, challenges during the process were revealed through the focus group findings. Because of the variety of student rotations, clinical sites, preceptors, type of patients seen, and health care delivery systems experienced during immersion, it is difficult to standardize the evaluation of this part of the program, so using a focus group format to solicit immersion feedback was built into the evaluation plan. Many indirect clinical experiences in DNP education cannot be duplicated and often occur only in the clinical setting. Thus, continuous program evaluation and revision are essential toward positioning students to attain competency in the most efficacious manner possible.

\section{References}

American Association of Colleges of Nursing. (2006). The essentials of doctoral education for advanced nursing practice. Retrieved from http://www.aacn.nche.edu/education-resources/essential-series

American Association of Colleges of Nursing. (2015). The doctor of nursing practice: Current issues and clarifying recommendations. Retrieved from http://www.aacn.nche.edu/news/articles/2015/ dnp-white-paper

Brown, M. A., \& Crabtree, K. (2013). The development of practice scholarship in DNP programs: A paradigm shift. Journal of Professional Nursing, 29, 330-337.

Carper, B. A. (1978). Fundamental patterns of knowing in nursing. Advances in Nursing Science, 1(1), 13-23.

Clark, R. C., \& Allison-Jones, L. (2011). The doctor of nursing practice graduate in practice. Clinical Scholars Review, 4(2), 71-77.

Commission on Collegiate Nursing Education. (2013). Standards for accreditation of baccalaureate and graduate nursing programs. Washington, DC: Author.

Institute of Medicine. (2011). The future of nursing: Leading change, advancing health. Washington, DC: National Academies Press.

Kendall-Gallagher, D., \& Breslin, E. (2013). Developing DNP students as adaptive leaders: A key strategy in transforming health care. Journal of Professional Nursing, 29(5), 259-263.

Riley, J., \& Beal, J. (2013). Scholarly nursing practice from the perspectives of early-career nurses. Nursing Outlook, 61(2), e16-e24.

Correspondence regarding this article should be directed to Sheila Grossman, PhD, FNP-BC, APRN, FAAN, professor and coordinator, family nurse practitioner program, director, evaluation, faculty scholarship and mentoring, Fairfield University, Marion Peckham Egan School of Nursing and Health Studies, Fairfield, CT 06824. E-mail: Sgrossman@fairfield.edu 
Reproduced with permission of the copyright owner. Further reproduction prohibited without permission. 